\title{
Design and Psychometrics of Tools for Measuring the Consequences of Virtual Social Networks on Married Life
}

\begin{abstract}
Background and Objective: Couples' communication interactions in the context of social networks have been challenged. The aim of this study was to evaluate the validity and reliability of a tool for measuring the consequences of virtual social media on marital life by factor analysis.

Materials and Methods: This tool is a qualitative methodology based on the exploration of views and perceptions of married men and women about the consequences of virtual social networks on married life. The validity of the questionnaire was assessed through face validity (qualitative and quantitative), content validity (qualitative and quantitative) and construct validity (exploratory and confirmatory factor analysis) in 700 married individuals. The reliability of the questionnaire was determined by the test-retest method (calculation of intra-class correlation coefficient) and internal correlation (calculation of Cronbach-alpha coefficient). Statistical analysis was performed by SPSS24 and AMOS24 software. Results: The initial instrument consisted of 20 items from a qualitative study, which after psychometrics, 4 items were removed and 12 items remained. The range of values calculated for the ratio and content validity index of the items were (0.83-1) and (0.66-1), respectively, and the impact score of all of them was higher than 1.5. The Intra-class correlation coefficient and Cronbach's alpha coefficient of the questionnaire were obtained at 0.864 and 785 , respectively. The results of exploratory factor analysis were four factors: "Threat of marital commitment», "individualization of cohabitation"," Threat to privacy" and "Faded intimacy". In confirmatory factor analysis the fitted model based on these four factors explained $43.75 \%$ of the consequences of social media presence on coupless lifestyle.

Conclusion: Psychometric results in this study showed that a tool with 20-iteme and 4 domains for measuring the consequences of social media presence on couples' lifestyles has good validity and reliability and it can be used as a suitable tool in this field.
\end{abstract}

Keywords: Psychometrics, Tools, Social Networking, Couples, Factor Analysis Paper Type: Research Article.

Citation (Vancouver): Yarahmadi S, Kazemi S, Roozbehani N, Zarei F. Design and Psychometrics of Tools for Measuring the Consequences of Virtual Social Networks on Married Life. Iran J Health Educ Health Promot. Winter 2022;9(4): 350-359.

- Citation (APA): Yarahmadi S., Kazemi S., Roozbehani N., Zarei F. (Winter 2022). Design and Psychometrics of Tools for Measuring the Consequences of Virtual Social Networks on Married Life. Iranian Journal of Health Education \& Health Promotion., 9(4),350-359.
Saeed Yarahmadi

Department of Health Education and Health Promotion School of Health, Zanjan University of Medical Sciences, Zanjan , Iran.

Sara Kazemi

PhD Student, Department of Health Education and Health Promotion, Faculty of Medical Sciences, Tarbiat Modares University, Tehran, Iran.

Nasrin Roozbehani

Associate Professor, Department of Health Education and Health Promotion, School of Health, Arak University of Medical Sciences, Arak, Iran

Fatemeh Zarei

* Assistant Professor, Department of Health Education and Health Promotion, Faculty of Medical Sciences, Tarbiat Modares University, Tehran, Iran (Corresponding Author) :

f.zarei@modares.ac.ir

Received: 2021/06/25

Accepted: 2021/08/20

Doi: 10.52547/ijhehp.9.4.350 


\section{طراحى و روانسنجى ابزار اندازهكيرى بيامدهاى شبكههاى اجتماعى مجازى بر زندكى زوجى}

سعيد يار احمدى

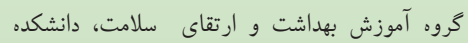

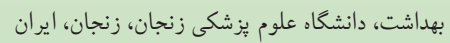
سار كاظمى دانس

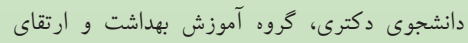

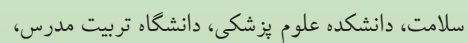
تهران، ايران،

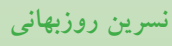

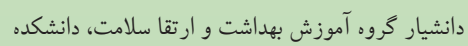

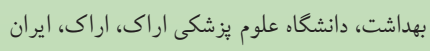

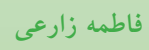
* *استاديار كروه آموزش بهداشت و ارتقائ سلامت،

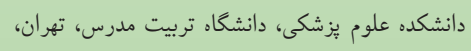
f.zarei@modares.ac.ir

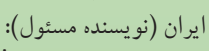

تاريخ دريافت: تارئ تاريخ يذيرش:

\section{كبكيله}

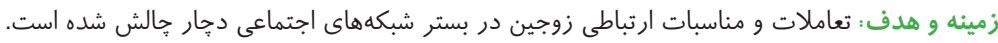

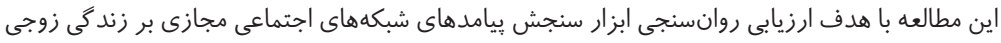
با روش تحليل عاملى انجام شده است.

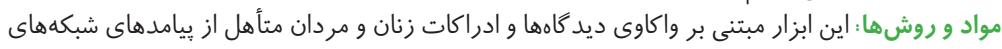

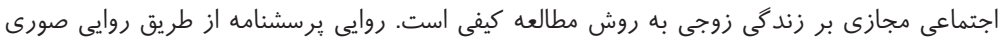

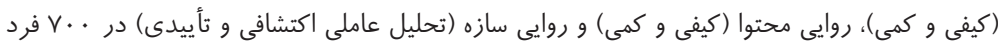

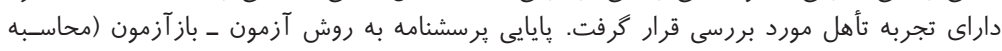

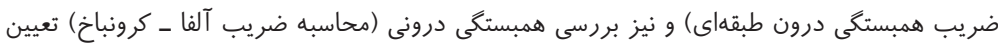

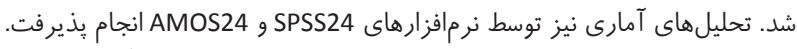

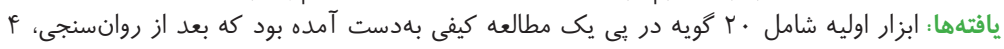

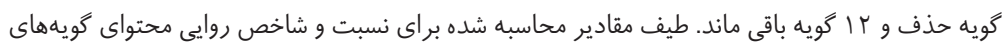

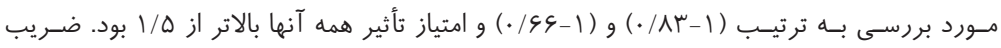

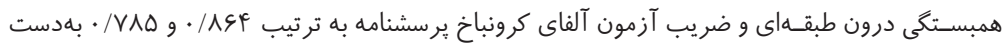

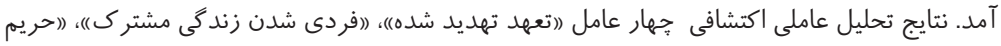

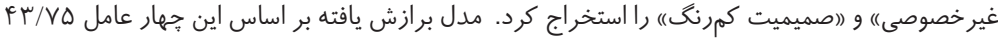

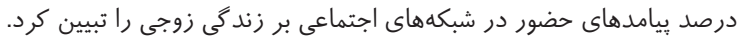

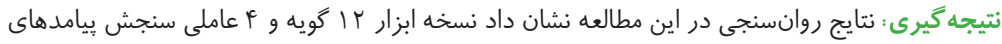

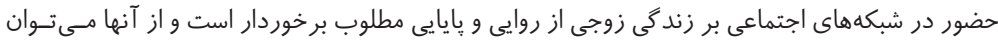

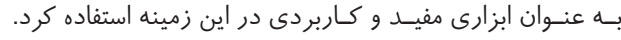

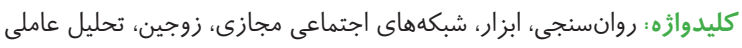

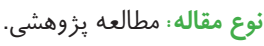

4 استناد (ونكوور): يار احمدى س، كاظمى س، روزبهانى ن، زارعى ف. طراحى احى و روانسنجى ابزار

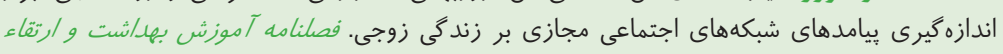

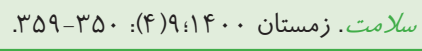

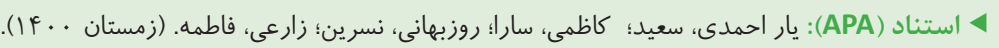

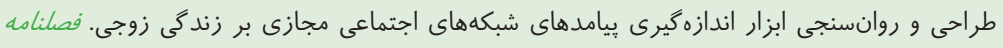

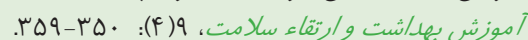


خانوادگى همراه بوده است و افرادى كه بيشتر از اينترنت استفاده

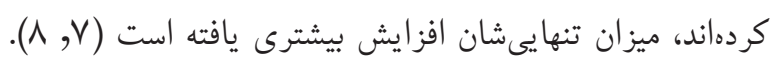

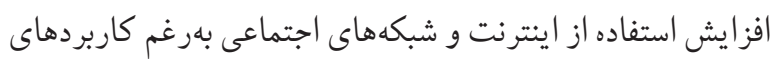

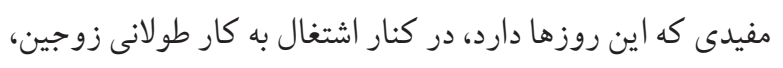

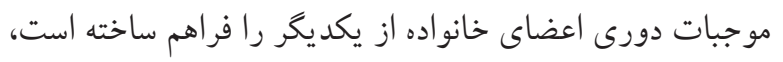

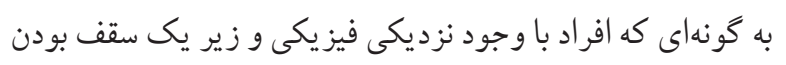

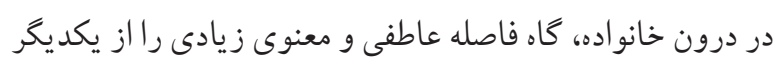

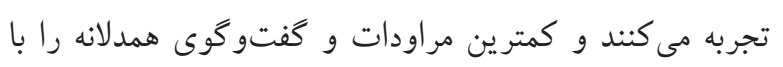

$$
\text { يكديخر دارند (ه, } 9 \text { (ه). }
$$

مطالعات نشان داده است كه رسانههاى اجتماعى به بالاترين

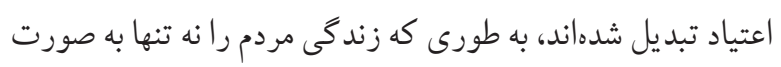

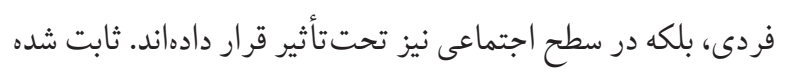

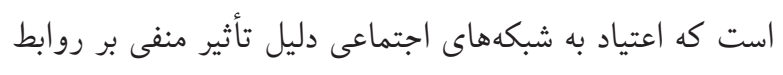

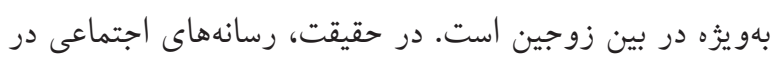

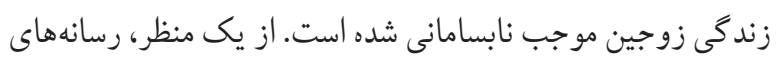

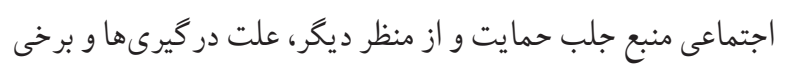

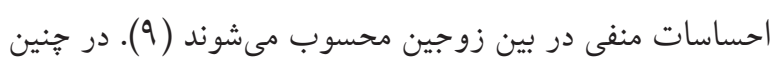

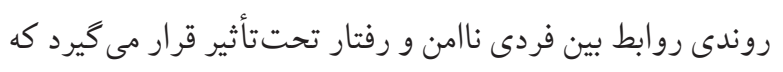

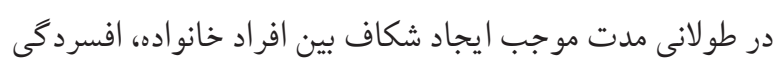

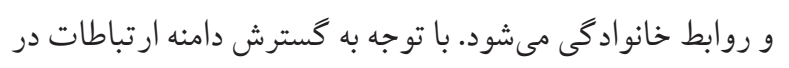
شبكهاى اجتماعى، برقرارى ارتباط با جنس مخالف بسيار آسان شده است، و اين سهولت مىتواند تعهد زوجين را تهديد كند (9) (9).

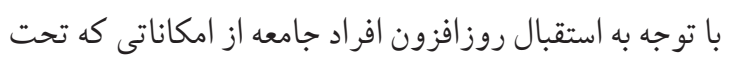
عنوان شبكههاى اجتماعى و رسانهاى جديد براى برقرارى تعاملات

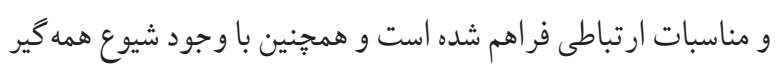

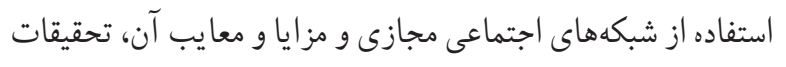
محدودى در اين زمينه وجود دارد. با توجه به ساختار جمعيتى جوان

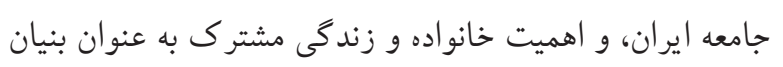
اصلى جامعه، شناخت، بيشخيرى و درمان هر عاملى كه بر سبك ونى إنى زندكى زوجين تأثير داشته باشد، الزامى به نظر مى بـ درسد.
فناورى اطلاعات و ارتباطات به يكى از مهمترين نيروها و ابزارهايى

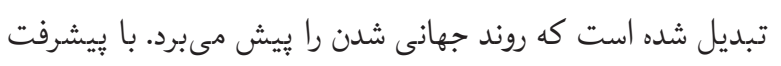

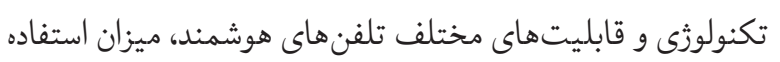

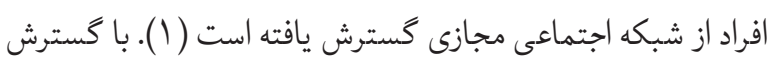

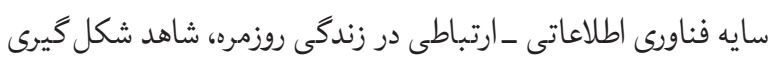
نسل جديدى از ابزارهاى مبتنى بر اينترنت هستيم كه شبكههاى

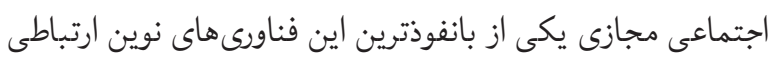

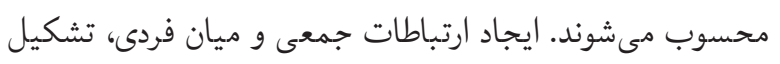

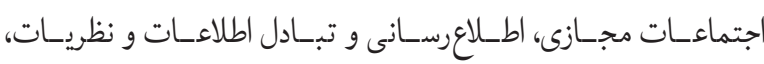

شناخته شدهترين كاركردهاى اين شبكه ها به شمار مىروند (Y). تغيير رفتار فردى، عاطفى، خانوادگى و اجتماعى كاربران

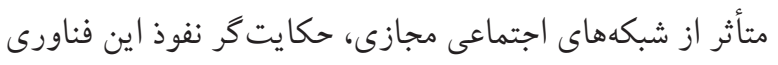

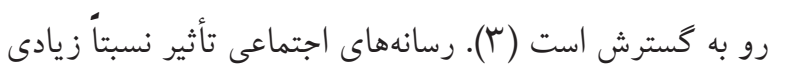

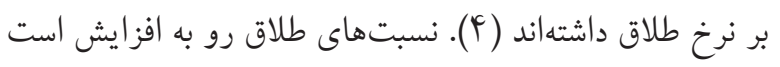

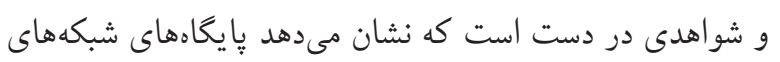

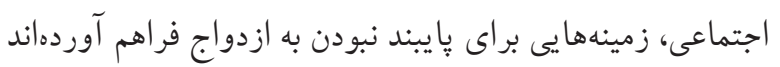

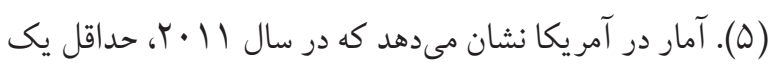

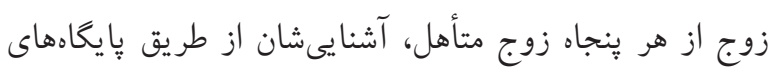

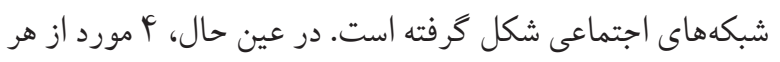

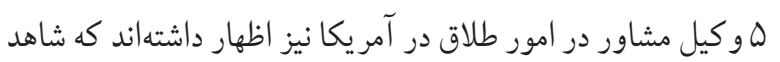
افزايش موارد طلاق مرتبط با شبكههاى اجتماعى بودهاند. استفادئ

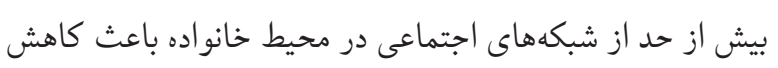

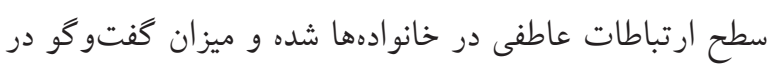
خانواده را حتى از ها دقيقه در روز هم كمتر كرده است (ه, و ؟).

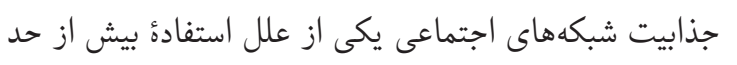
از اين شبكها است كه موجب شده اغلب كاربران اين شبكهها،

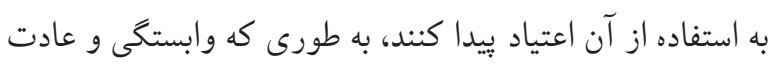

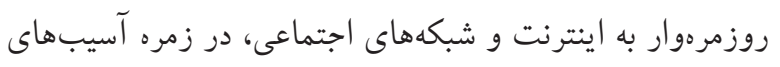

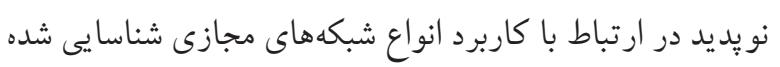

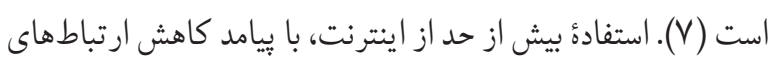


و فردى شدن زندكى مشترك) طراحى شد. اين يرسشنامه با طيف ليكرت سه گزينهاى شامل مخالفم با | امتياز، نظرى ندارم ب امتياز

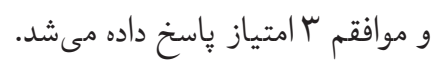
روانسنجى ابزار

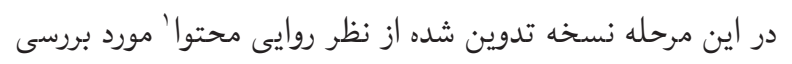
قرار گرفت. روايى محتوا به دو روش كيفى و كمى انجام شد. در سرد

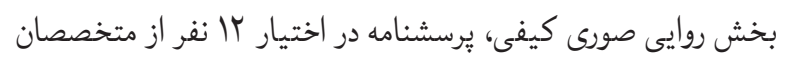

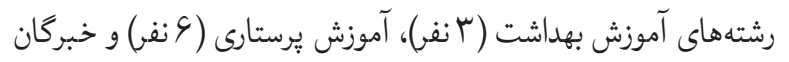

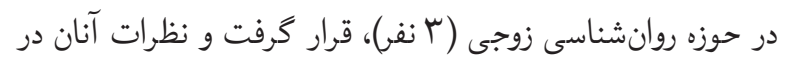

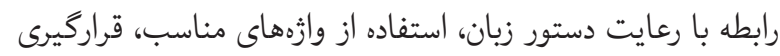

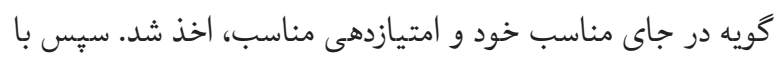
در نظر گرفتن نظرات و ييشنهادات خبركان، بازنويسى، اصلاحات و تغييرات بيشنهادى در گويهها انجام شد. در بررسى روايى محتوا به صورت كمى، ابتدا يرسشنامه اوليه

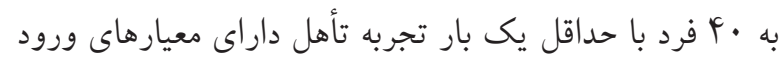

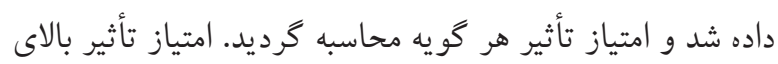

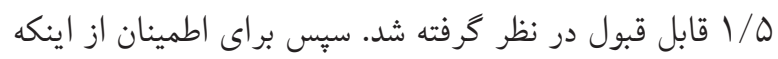

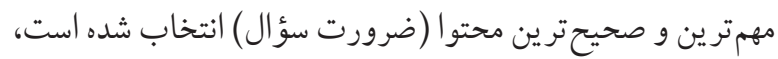
از نسبت روايى محتوا؟ و براى اطمينان از اينكه كويههاى ابزار

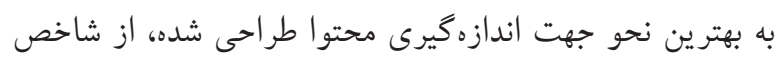

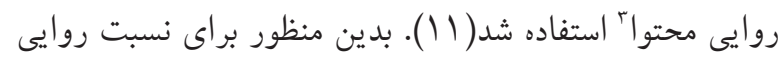

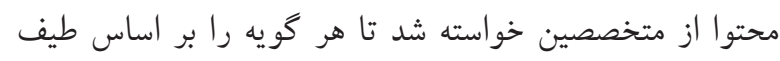

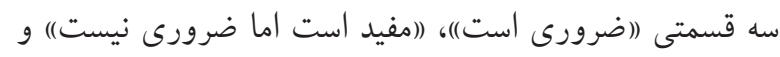
(ضرورى نيست)) بررسى كنند. مقادير نسبت روايى محتوا بالاتر

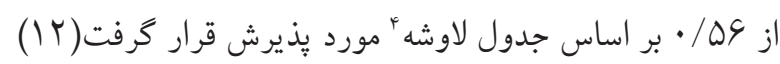

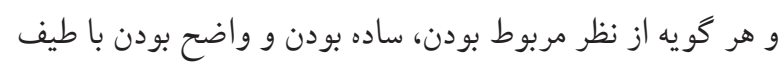

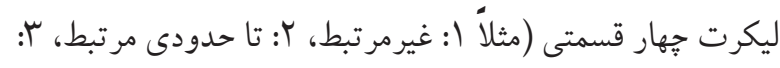

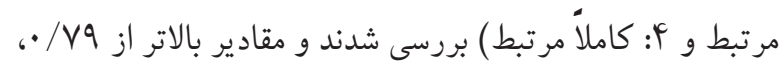

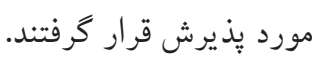

1. Content Validity

2. Content validity ratio (CVR)

3. Content validity index (CVI)

4. Lawshe
از آنجا كه مرورى بر مطالعات كذشته نشان داد كه ابزار مناسبى

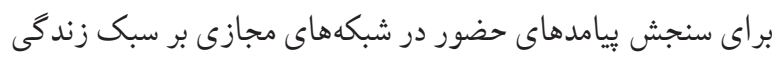

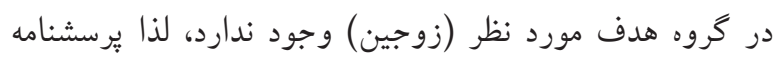

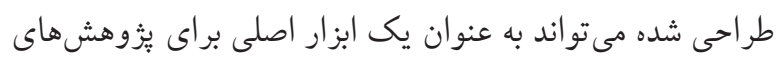
توصيفى و برنامهريزى آموزشى مورد استفاده محققان قرار كيرد.

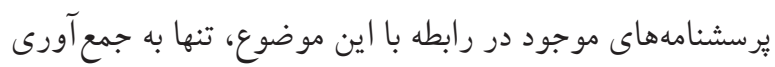

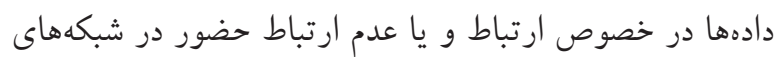
اجتماعى و روابط زوجين تبرداخته و بيامدهاى آن را بررسى نكردهاند. نتايج مطالعه حاضر به بدنه دانش موجود در زمينه يُيامدهاى حضور

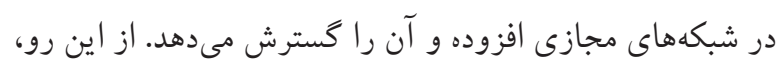

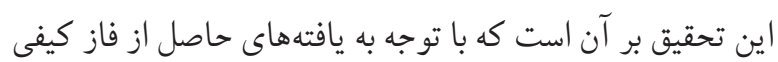

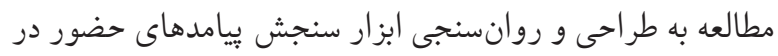
شبكهاى اجتماعى بر سبك زندگى زوجين بيردازد. مو اد و روشها اين مطالعه به صورت مقطعى ـ تحليلى بر روى . V. فرد با تجربه

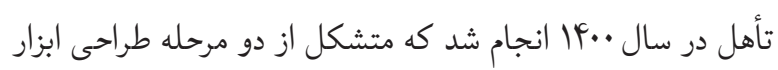

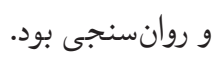
طرحى ابزار ابزار حاضر حاصل از يافتهاى مطالعه كيفى با هدف واكاوى

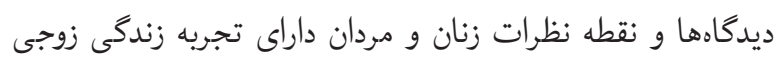

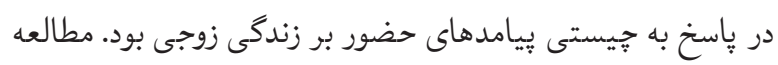

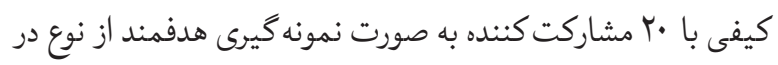

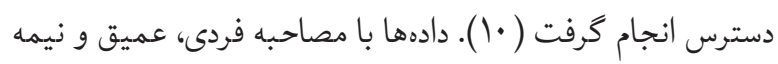

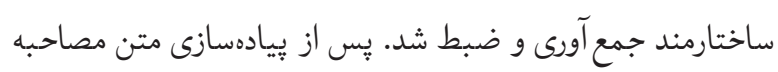
بر اساس مراحل تحليل محتواى كرانهايم مورد تحليل قرار كرفت.

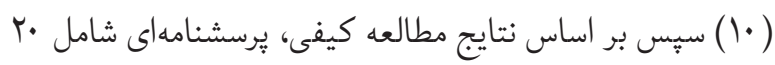
كويه در ارتباط با ييامدهاى مختلف شبكههاى اجتماعى مجازى بر زندگى زوجين بر اساس شش طبقه استخراج شده از مطالعه

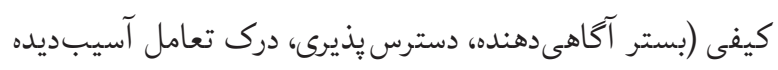
بين زوجين، خيانت خزنده و نامحسوس، حريم زوجى تهديد شده، 
شد. شاخص ريشه ميانكين مربعات خطاى بر آورد كمتر از ^ • / •

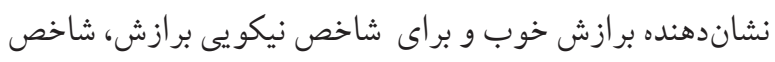

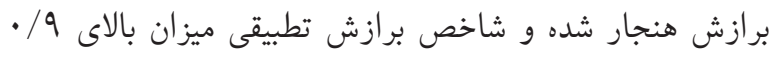
نشاندهنده برازش خوب مدل مى باشد. نسبت كاى دو به درجه

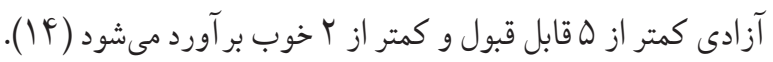

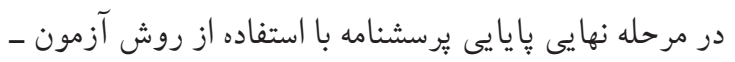

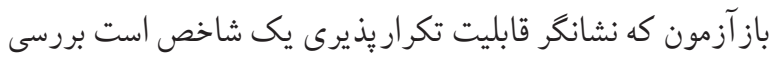

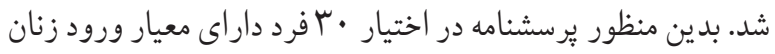

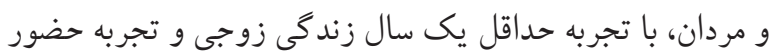

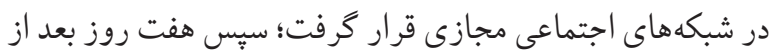

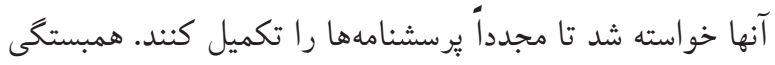

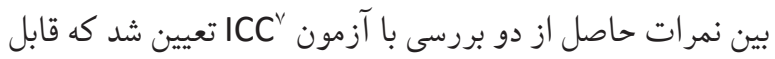
قبول ترين آزمون جهت ثبات ابزار است. جنانجه اين شاخص بين

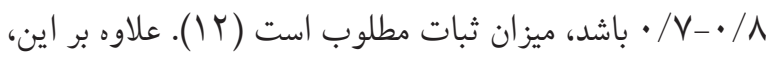

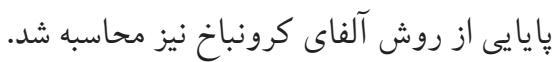

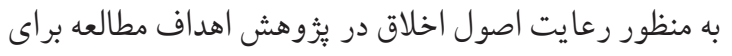
شر كت كنند كان و اطمينان از محرمانه بودن اطلاعات آنها توضيح

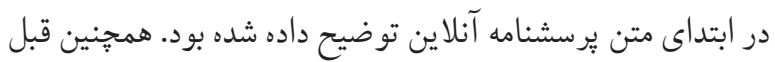

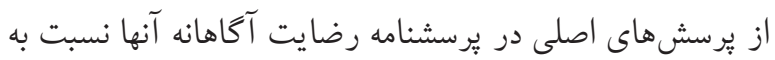
تكميل برس سشنامه اخذ شد.

يافتهه ها

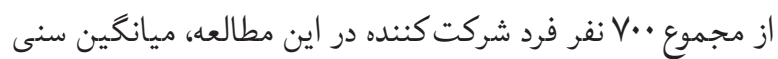

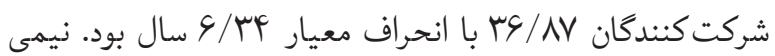

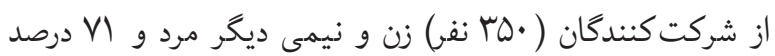

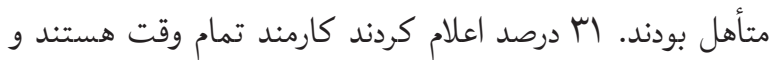
تحصيلات افراد مورد بثوهش با وه درصد و تحصيلات همسر آنها با اله درصد در سطح كارشناسى بيشترين سطح تحصيلى در بين ساير سطوح تحصيلى بود. وضعيت اقتصادى أf درصد از زوجين در سطح مطلوب گزارش گرديد. (جدول شماره ()

7. Intra-class coefficient correlation
براى بررسى روايى سازه برسشنامه از تحليل عامل اكتشافى

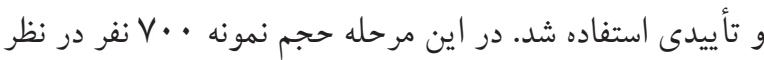

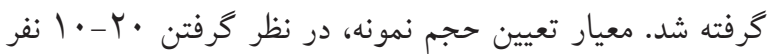
براى هر گويه(1) و (1) تقسيم تصادفى نمونهها براى انجام تحليل

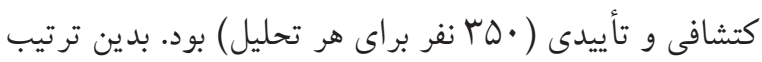

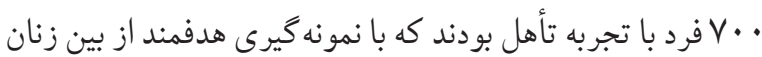

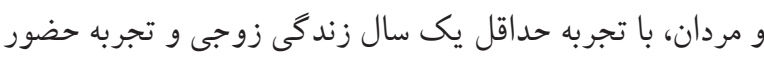

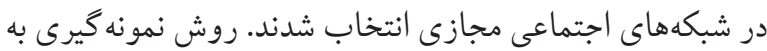
اين شكل بود كه برسشنامه به صورت آنلاين به طرق مختلف (از

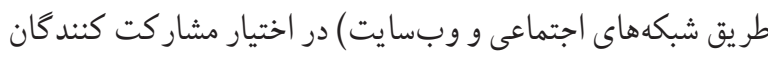
قرار گرفت. به اين شيوه كه لينك يرسشنامه در بيج اينستاگر امى و و

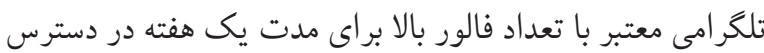
عموم قرار كرفت. بعد از دريافت پاسخ ها، تحليل عامل اكتشافى به روش مؤلفههاى

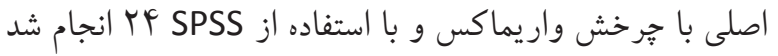
و شاخصهاى مو رد استفاده شاخص كيزر -مير -اولكين' و آزمون كرويت بارتلت بودند. شاخص KMO نشاندهنده كفايت نمونه گيرى مودي

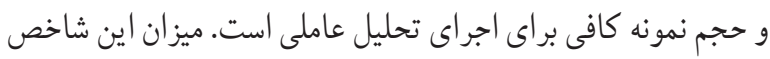

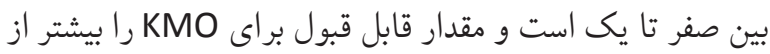

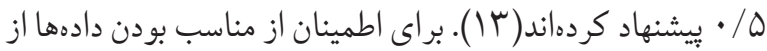
آزمون كرو يت بارتلت استفاده شد كه اين آزمون، معنادارى تحليل دادهها را مىسنجد و در سطح معنادارى 90/ • در نظر كرفته شد.

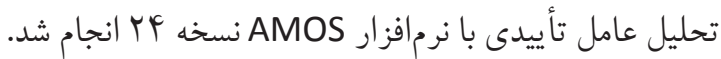
جهت برازش مدل از شاخصهاى مجذور كاى به درجه آزادى، ريشه تانه

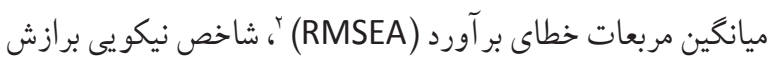

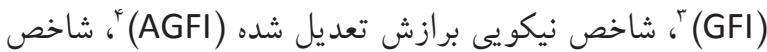
برازش هنجار شده (NFI) و و شاخص بر ازش تطبيقى (CFI) "استفاده

2. Root Mean Square Error of Approximation:

3. Goodness Fit Index

4. Adjusted Goodness Fit Index

5. Normal Fit Index:

6. Comparative Fit Index 
بزر كتر از عدد مشخص شـده در اسـتاندارد جدول لاوشه ( O9 • •)

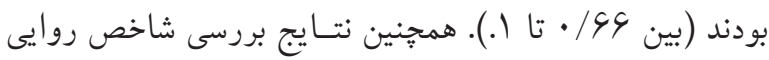

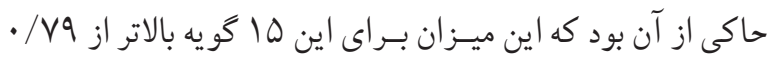

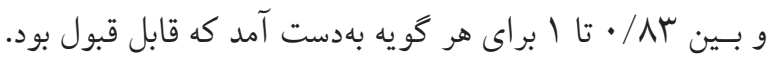

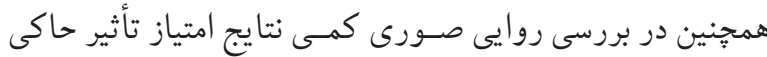

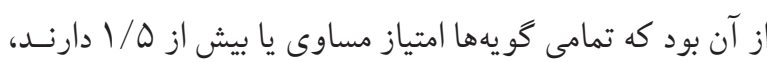

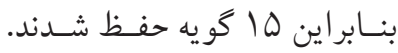

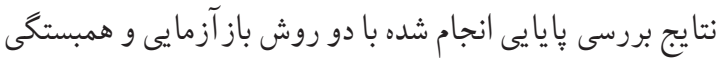

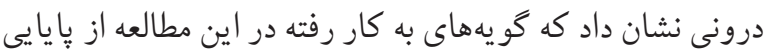

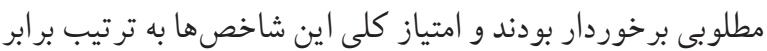

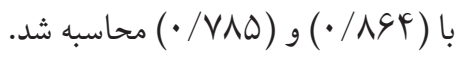
در بررسى روايى سازه، بر اساس نتايج تحليل عاملى اكتشافى ابعاد

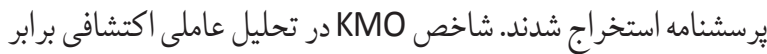
با بود كه كفايت حجم نمونه را تأييد كرد. با روش حداكثر درست نمايى و با با استفاده از جرخش واريماكس و همجنين نمودار سنكر يزه، جهار عامل (اتعهد تهديد شده))، ((فردى شدن زندكى مشتر ))، (احريم غيرخصوصى)) و (اصميميت

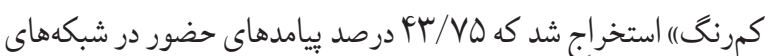
اجتماعى بر سبك زندگى زوجين را تبيين كردند. (جدول Y).
جدول ا : مشخصات دموگرافيك افراد مورد مطالعه و ارتباط آنها

\begin{tabular}{|c|c|c|}
\hline \multirow[b]{2}{*}{ درصد (\%) } & \multicolumn{2}{|l|}{ متغير } \\
\hline & ميانكين (انحراف معيار) & سن \\
\hline$(\Delta \cdot) \mu \Delta \cdot$ & 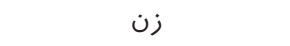 & \\
\hline$(\Delta \cdot))^{m} \cdot$ & مرد & سمي \\
\hline$(V I) \& 9 V$ & متأهل & \\
\hline$(r \mid) \backslash \Delta r$ & مطلقه و بيوه & تجربهتأهل \\
\hline$(V) \Delta$. & ازدواج موقت & \\
\hline (rI) rIV & كار مند & \\
\hline$($ HF $)$ YFF & ازاد & 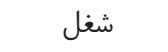 \\
\hline$(r \mu) r \mu q$ & بيكار - زن خانهدار & \\
\hline$(1 s) \mid r s$ & دييلم & . \\
\hline$(\Lambda F) \Delta V^{F}$ & دانشگاه & سونا \\
\hline$(r \Delta) \backslash \wedge \mid$ & بسيار مطلوب & \\
\hline$(\mathbb{F} 1)$ rqr & مطلوب & وصعيت در \\
\hline$($ (Yq) YTV & نامطلوب & \\
\hline
\end{tabular}

در ابتدا يرسشنامه تدوين شده شامل • † كويه بود. بر اساس

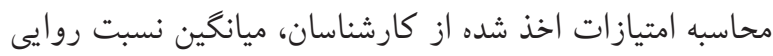
و شاخص روايى محتواى محاسبه شده براى كل ترسشنامه حاكى

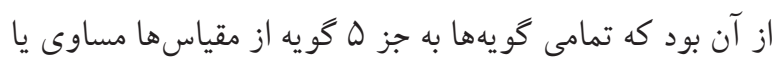

جدول ז: عوامل اكتشافى استخراج شده ير سشنامه سنجش يِيامدهاى حضور در شبكهاى اجتماعى بر سبك زندگى زوجين

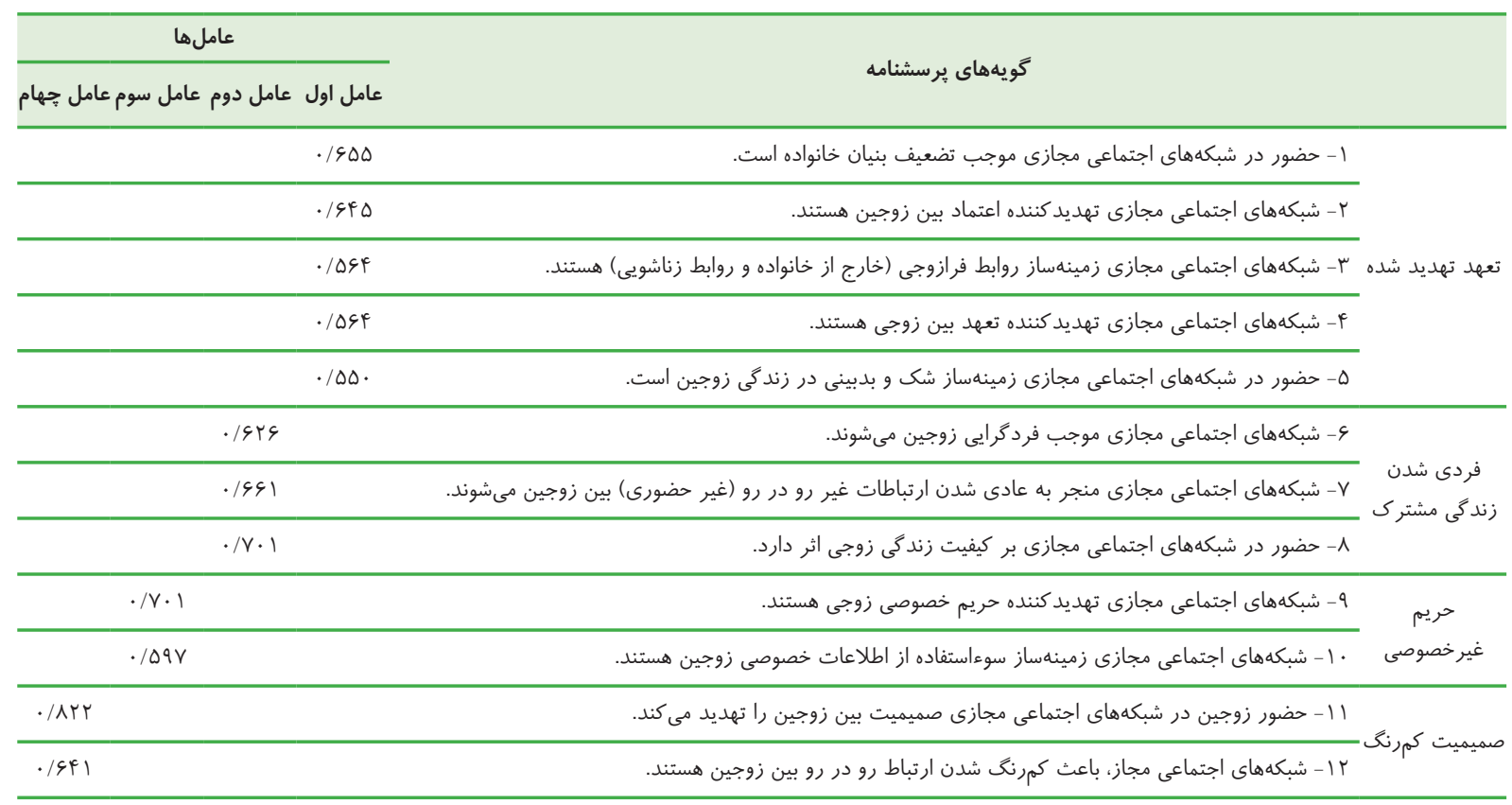




\section{بحث و نتيجه كيرى}

اين مطالعه با هدف ارزيابى روانسنجى ابزار سنجش بِيامدهاى

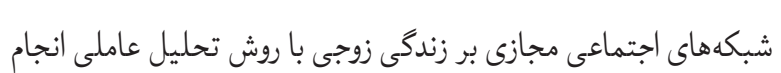

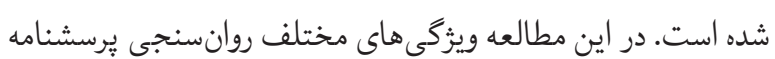
بيامدهاى حضور در شبكههاى اجتماعى بر سبك زندكى زوجين شامل: روايى صورى، روايى محتوا، روايى سازه و پايايى آن بررسى شده.

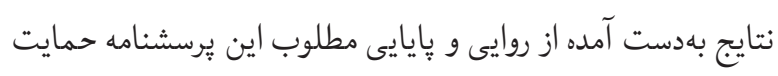

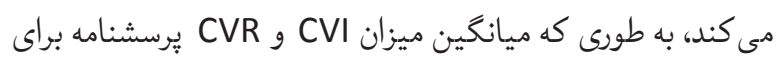

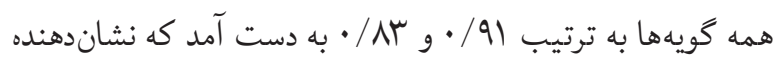
روايى مطلوب اين آزمون بود. در اين مطالعه، پايايى ابزار از طريق

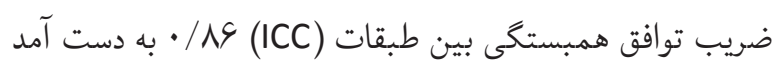

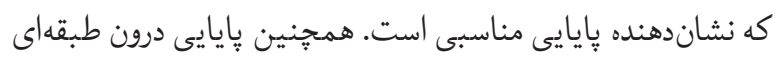

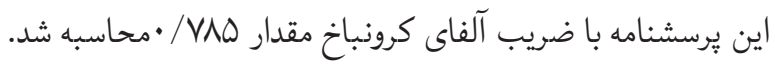

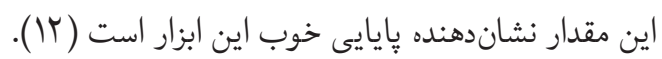

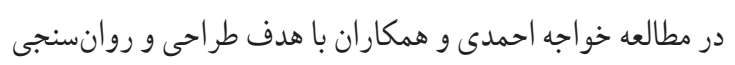
يرسشنامه اعتياد به شبكهاى اجتماعى مبتنى بر موبايل ميانخين

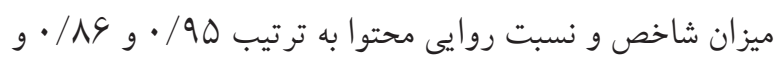

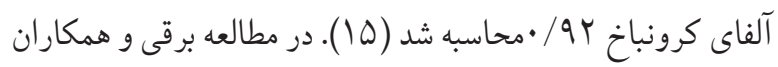
با هدف سنجش تأثير شبكههاى اجتماعى بر روابط زناشويى و ونان كيفيت زندگى زوجين در شيراز، ميزان شاخص و نسبت روايى سني

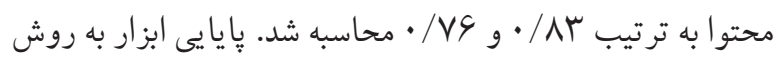

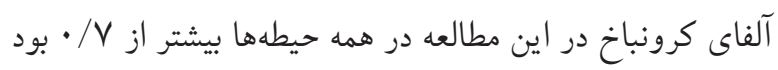

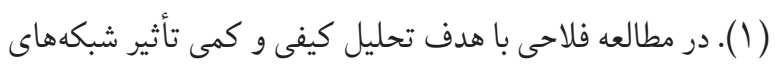

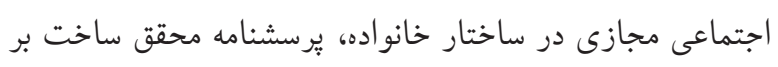

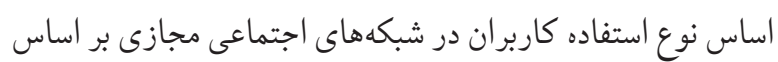

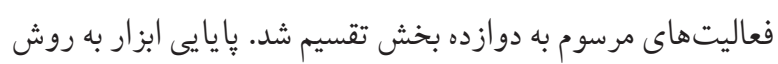

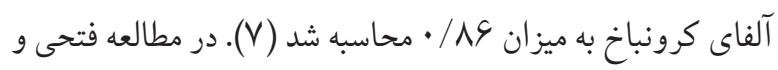

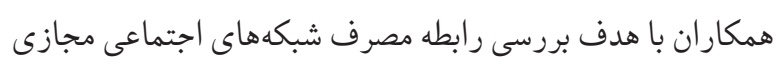

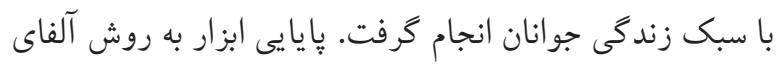

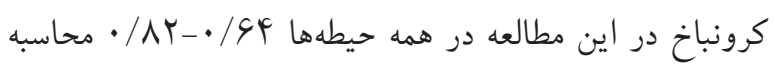

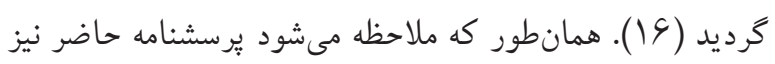

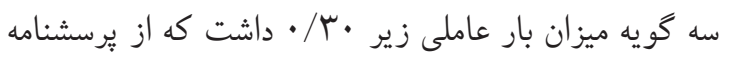
حذف شدند (سا (1). در مرحله بعد به منظور تأييد ساختار حاصل از باز

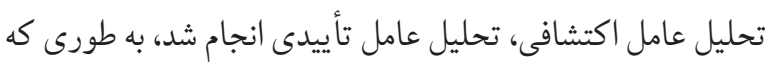

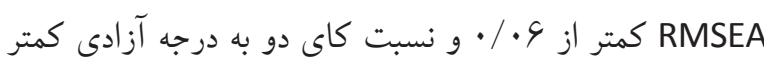

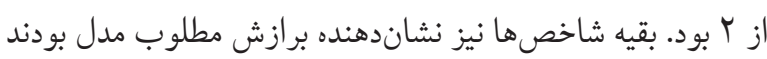

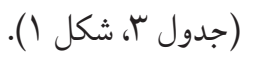

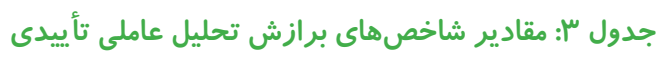

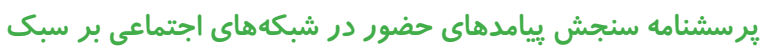
زندگى زوجين

\begin{tabular}{lccccccc}
\hline RMSEA & IFI & NFI & AGFI & GFI & CFI & df/Xr & P value \\
\hline.$/ . \mu \mathrm{r}$ &.$/ 9 \mathrm{Y}$ &.$/ \mathrm{AY}$ &.$/ 9 \mathrm{~V}$ &.$/ 9 \Lambda$ &.$/ 9 \mathrm{Y}$ & $\mathrm{I} / \mathrm{Ar}$ &.$/ \cdots 1$ \\
\hline
\end{tabular}
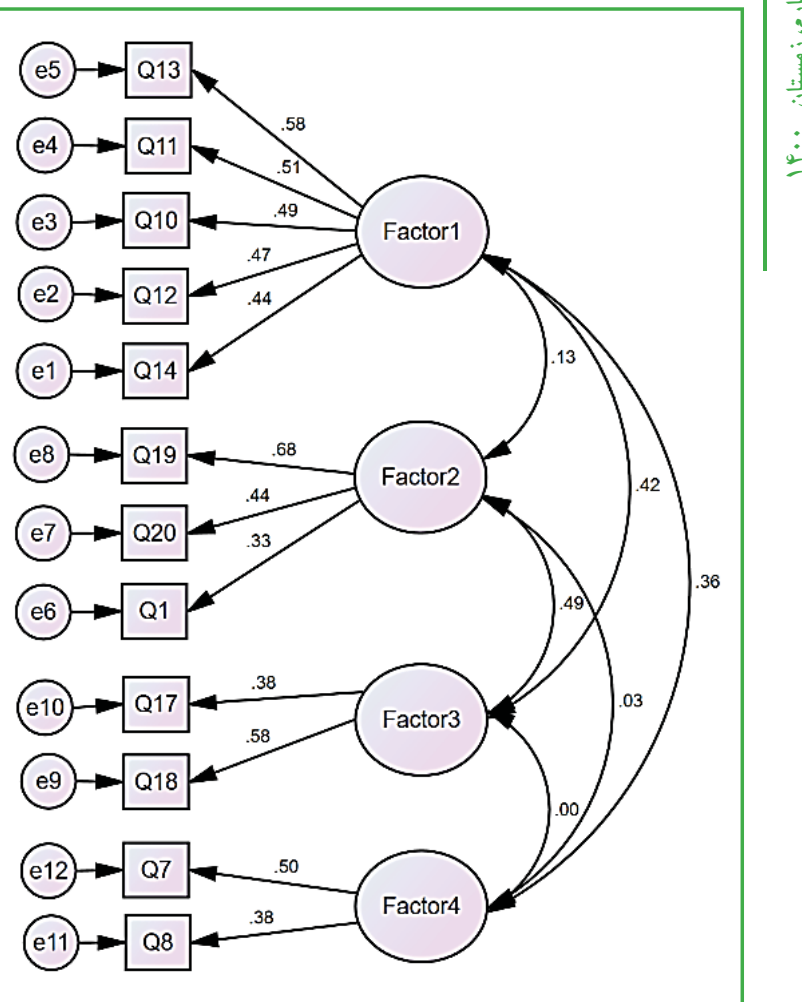

شكل ا: الكَوى تحليل عامل تأييدى يرسشنامه سنجش بِيامدهاى

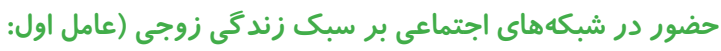

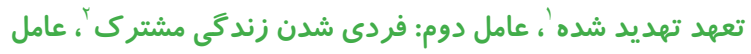

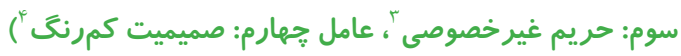

1. Threat of marital commitment

2. Threat to privacy

3. Faded intimacy

4. Individualization of cohabitation 
ـ نقشهاى جديدى از تعاملات جنسى را در فضاى اينترنت مانند

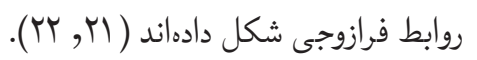

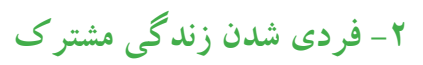
فردى شدن زندگى مشترى به واسطه حضور زوجين در شبكه

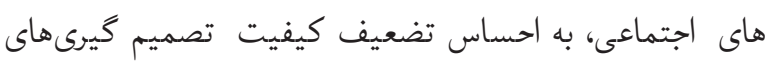

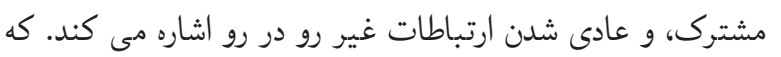

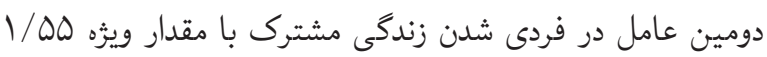

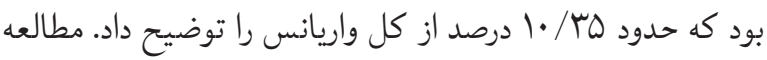
كروس و همكاران گزارش داد كه بين شبكههاى اجتماعى و روابط زناشويى و كيفيت زندگى رابطه معنادار و معكوس وجود دارد [ [Y9].

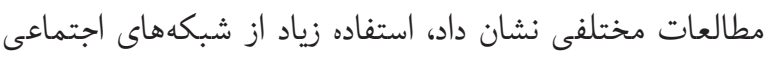

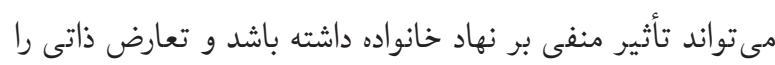

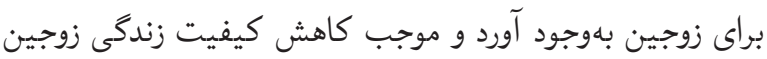

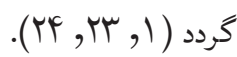
r- - حريم غير خصو صى (1)

مفهوم حريم غيرخصوصى به ادراى اثرتهديد كنندكى شبكههاى

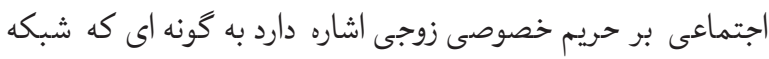

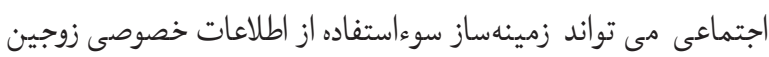
باشد. در اين مطالعه حريم غيرخصوصى، سومين عامل از بيامدهاى نوسين

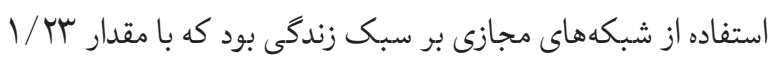

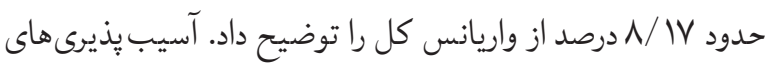

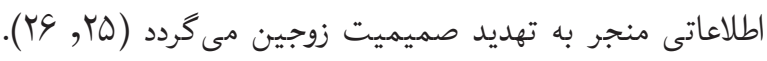
مصاديق نامنى در فضاى مجازى خانواده مىتواند به خطر افتادن

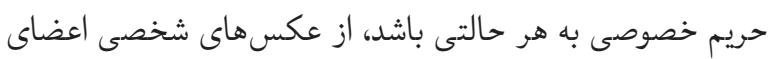
خانواده كرفته تا رازهاى اعضاى خانواده كه افشا شدن آنها مى تواند موجب ناامنى امنيت خانواده شود. اين موضوع ممكن است به دليل

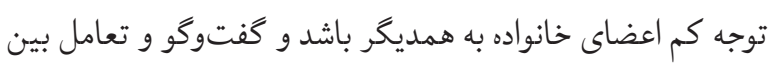
آنها را كاهش دهد (Y) (T). F عامل صميمت كمرنگ به بيامد تهديد كننده ديخر حضور زوجين در شبكههاى اجتماعى مجازى اشاره كرده و شبكههاى اجتماعى مجازى،
ماند يرسشنامههاى ديكر مرتبط داراى روايى و پِيايى مناسبى است. در مطالعه حاضر، در بررسى روايى سازه يرسشنامه با استفاده

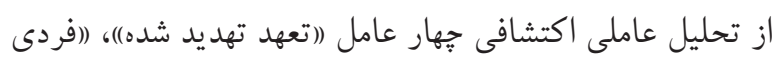
شدن زندگى مشتر ك)، (احريم غير خصوصى)) و ((صميميت كمرنگ))

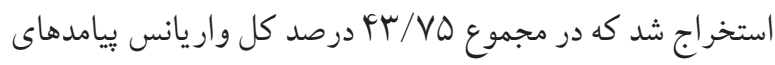
حضور در شبكههاى اجتماعى بر سبك زندگى زوجى را تبيين كردند

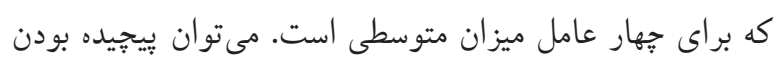

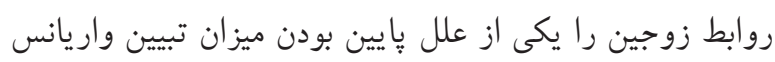
كل توسط اين جهار عامل دانست. 1 - تهايد درى شده

تهديد درك شده در اين مطالعه به احساس تهديدى كه زوجين نسبت

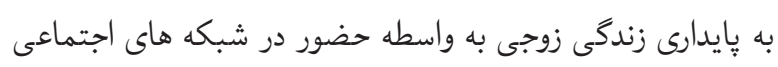

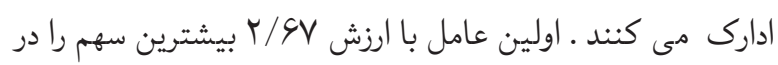
توضيح واريانس كل (V/VV) درصد داشت. برخى مطالعات ديكر

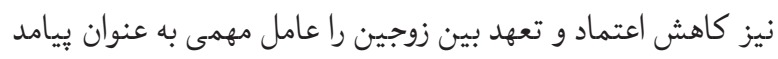

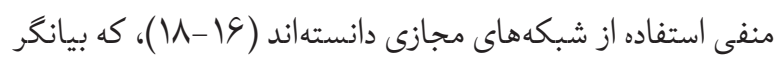

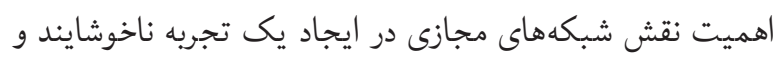
ايجاد شك و بدبينى بين زوجين است. هر جه ميزان استفاده از شبكههاى اجتماعى در ميان زوجين بيشتر شود و استفاده صحيح

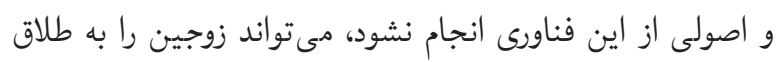

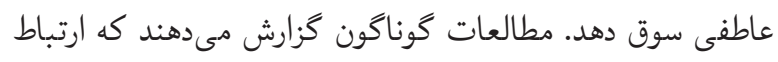

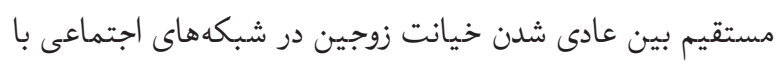

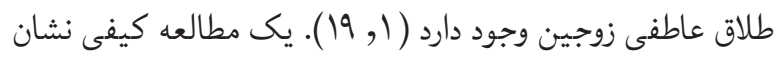
داده است كه شبكههاى اجتماعى تهديدهاى جدى خانوادگى، اخلاقى، فرهنكى، روحى و جسمى را براى كاربران جوان به همراه دارد (·r). نياز جنسى مدت هاست كه يكى از موضوعات اصلى در مطالعات

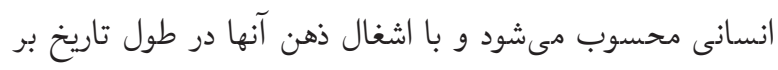

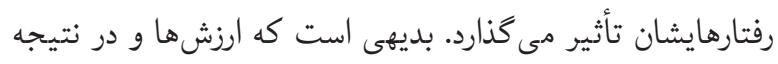
ارزشهاى جنسى، در جامعه ما تغيير كردهاند. جهانى شدن بهطور

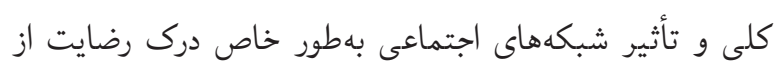
نيازهاى جنسى را دكركون كرده است و افراد ـ آكاهانه يا نآكاهانه 
همسانى طى زمان (آزمون - بازآزمون) تيرسشنامه • ب گويهاى مورد

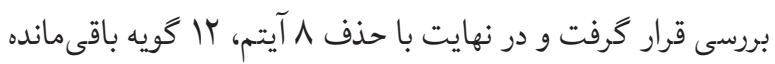

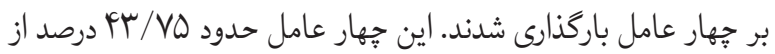
واريانس كل را تبيين كردند. بنابر نتايج به دست آمده، نسخه نهايى بهاي

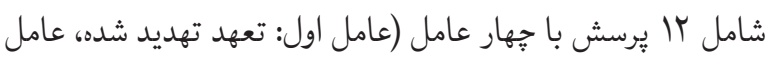
دوم: فردى شدن زندگى مشترك، عامل سوم: حريم غيرخصوصى، و و عامل جهارم: صميميت كمرنغ) جهت سنجش ييامدهاى حضور زوجين در شبكههاى اجتماعى دارايى روايى سازه و پايايى قابل قبول

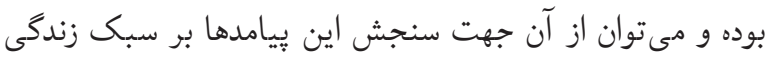

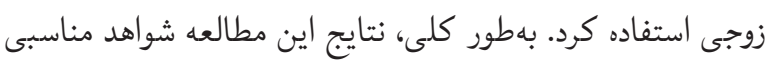

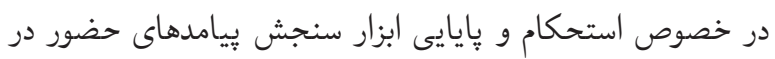
شبكههاى اجتماعى بر سبك زندكى زوجين، بر اساس انجام فرآيند روانسنجى مورد مطالعه فراهم نمود.

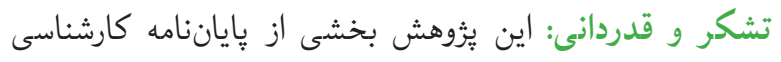

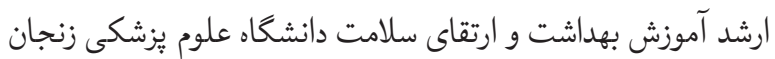

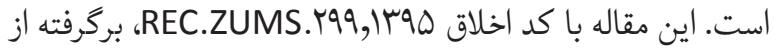

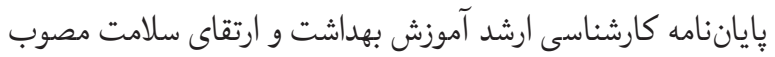

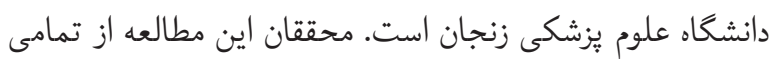

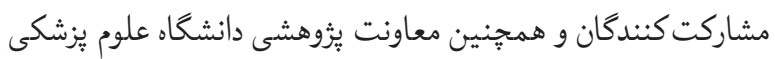

$$
\text { زنجان قدردانى مى كنند. }
$$

تضاد منافع: بدينوسيله نويسندگان اظهار مى كنند كه هيج گونه تضاد منافع در مطالعه حاضر وجود ندارد.

\section{References}

1. NaseriBooriAbadi T, Sadoughi F, Sheikhtaheri A. The Status of Electronic Health Literacy in people with Hearing Impairment: Content Analysis Approach. Journal of Health Literacy. 2021;6(3

2. Adlipour S, Mir Mohammad Tabar SA, Behjat Y. Facebook Social Network, Iranian Youth and Social Order: Secondary Analysis of Existing Research. Religion \& Communication. 2016;22(2):87-115.

3. Seifollahi S, Shateri P. The Role of New Social Networks in Changing the Behavior of Girls and Women in Iran (Case of Study: girls and women university students in Tehran in 2013). Iranian Social Development Studies. 2015;7(2):2744.
را باعث كمرنغ شدن ارتباط رو در رو بين زوجين مى داند. كمرنق

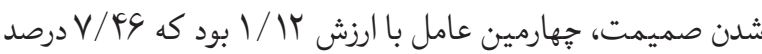

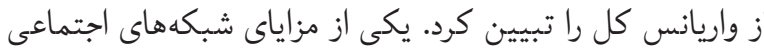
جنبه سركرم كننده بودن آن است. از آنجا كه امكانات تفريحى و ورئي

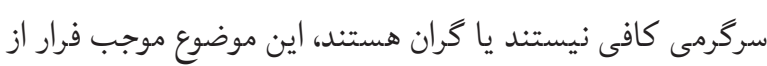

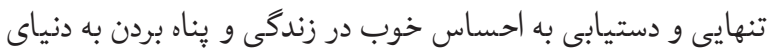
مجازى و اينترنت مىشود كه باعث كمرنح شدن ارتباط زوجين

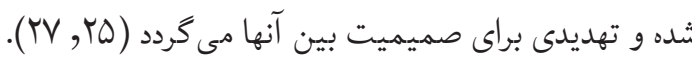

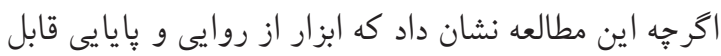

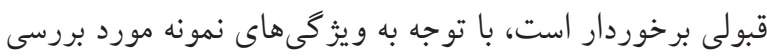

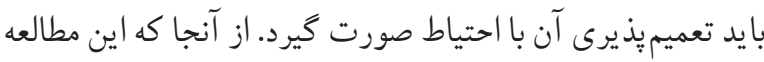

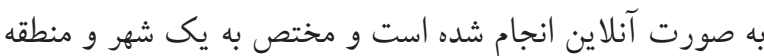

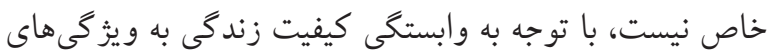

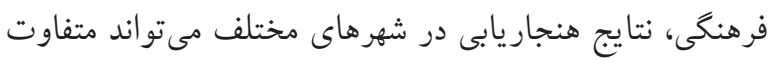

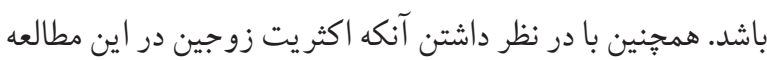
داراى تحصيلات دانشكاهى و شاغل در سازمان دولتى مىباشند، تعميم يذيرى نتايج به گروههاى داراى تحصيلات پايينتر و غير

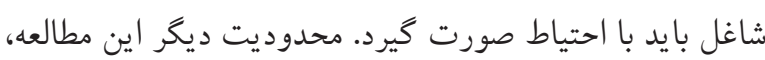
عدم انجام روايى ييشبينى كننده و همزمان بود، بنابراين توصيه مىشود در مطالعات آتى، اين نوع روايى نيز مدنظر قرار كيرد.

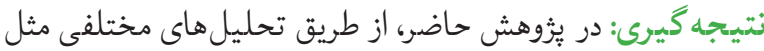
تحليل عاملى اكتشافى و تأييدى، همسانى درونى (آلفاى كرونباخ)،

4. Saleh M, Mukhtar J. Social media and divorce case study of Dutse LGA Jigawa State. IOSR Journal Of Humanities And Social Science. 2015;20(5):54-9.

5. Valenzuela S, Halpern D, Katz JE. Social network sites, marriage well-being and divorce: Survey and state-level evidence from the United States. Computers in Human Behavior. 2014;36:94-101. https://doi.org/10.1016/j.chb.2014.03.034

6. Clayton RB, Nagurney A, Smith JR. Cheating, breakup, and divorce: Is Facebook use to blame? Cyberpsychology, Behavior, and Social Networking. 2013;16(10):717-20. https://doi.org/10.1089/cyber.2012.0424 PMid:23745615 
7. Yoshany N, Mazloomy-Mahmoodabad S-S, Mihanpour H, Seyed-khameshi S-s, Gerayllo S, Nabil A. The Role of Using Smartphones on Depression Rate in Retired Elderly. Iranian Journal of Health Education and Health Promotion. 2020;8(3):240-8. https://doi.org/10.29252/ijhehp.8.3.240

8. Gull H, Iqbal SZ, Al-Qahtani S, Alassaf RA, Kamaleldin MM. Impact of social media usage on married couple behavior a pilot study in Middle East. International Journal of Applied Engineering Research. 2019;14(6):1368-78.

9. Cravens JD, Whiting JB. Clinical implications of internet infidelity: Where Facebook fits in. The American Journal of Family Therapy. 2014;42(4):325-39. https://doi.org/10.1080/01926187.2013.874211

10. Mayring P. Qualitative content analysis: Theoretical background and procedures. Approaches to qualitative research in mathematics education: Springer; 2015. p. 365-80. https://doi.org/10.1007/978-94-017-9181-6_13

11. Kyriazos TA. Applied psychometrics: sample size and sample power considerations in factor analysis (EFA, CFA) and SEM in general. Psychology. 2018;9(08):2207. https://doi.org/10.4236/psych.2018.98126

12. Lawshe $\mathrm{CH}$. A quantitative approach to content validity. Personnel psychology. 1975;28(4):563-75. https://doi.org/10.1111/j.1744-6570.1975.tb01393.x

13. Nejatian M, Tehrani H, Momeniyan V, Jafari A. A modified version of the mental health literacy scale (MHLS) in Iranian people. BMC psychiatry. 2021;21(1):1-11. https://doi.org/10.1186/s12888-021-03050-3 PMid:33485306 PMCid:PMC7824912

14. Brown TA, Moore MT. Confirmatory factor analysis. Handbook of structural equation modeling. 2012:361-79.

15. Khajeahmadi M, Pooladi S, Bahreini M. Design and assessment of psychometric properties of the Addiction to Mobile Questionnaire Based on Social Networks. Iranian Journal of Psychiatric Nursing. 2016;4(4):42-50.

16. Fathi S, Vosughi M, Salmani G. Investigating the relationship between using virtual social networks and youth lifestyles (Case study: Khalkhal youth). QJ Sociol Stud Youth. 2016.

17. Rahimi M, shekarbeugi A, saroukhani B, Zahra Hazrati somee. Sociological study of the relationship between virtual social networks and current changes in couples marriages in a Tehran city. Journal of Socio-Cultural Changes 2016;13(4):1-18.
18. Arabi Mahdi. Investigating the Relationship between Using Virtual Mobile Social Networks and Emotional Divorce of Couples (Case Study of Isfahan). Isfahan Police Science Quarterly. 2017;4(12):40-63.

19. Prabu D, Stafford L. A relational approach to religion and spirituality in marriage: The role of couples' religious communication in marital satisfaction. Journal of Family Issues. 2015;36(2):232-49. https://doi.org/10.1177/0192513X13485922

20. Mahdizadeh M, Solhi M, Azar FE, Taghipour A, Farid AA. Psychosocial experiences of the internet in a group of adolescents: A qualitative content analysis. Medical journal of the Islamic Republic of Iran. 2017;31:46. htt ps://doi .org/10.14196/mjiri.31.46 PMid:29445675 PMCid:PMC5804448

21. Farahmand $M$, Javaherchian $N$, Javaherchian $L$. Globalization of culture and rethinking of sexual interactions; a case study of the youth in Yazd. Strategic Studies of public policy. 2014;5(14):175-204.

22.BeckerM.Privacyinthedigitalage:comparingand contrasting individual versus social approaches towards privacy. Ethics and Information Technology. 2019;21(4):307-17. https://doi.org/10.1007/s10676-019-09508-z

23. Levy $K$, Schneier B. Privacy threats in intimate relationships. Journal of Cybersecurity. 2020;6(1):tyaa006. https://doi.org/10.1093/cybsec/tyaa006

24. Nakhshipour E, Ebrahimpour D. Relationship between presence and activity in cyberspace with marital adjustment among married men and women referring to counseling centers in Urmia. Woman anf Family Studues. 2018;11(39):133-53.

25. Onsroudi E, Hosseinian PD, S., Salehi F, Mo'meni F. The Interrelationship of Internet Addiction, Adolescents' Conflict with Parents, Multidimensional Perceived Social Support, and Happiness. Quarterly Journal Of Family and Research. 2013;10(3):77-94.

26. Hashemi S, Soltanifra M, Soltanifar M. The Impact of Social Networks on Relationship between Spouses in Iran. OIDA International Journal of Sustainable Development. 2017;10(05):55-62.

27. Odin $\ddot{A} f$ AN. On the Right to Privacy and Family Life in the Context of Globalization and the Digital Era. Ovidius University Annals, Economic Sciences Series. 2020;20(2):177-83. 